\title{
STRATEGI PENGEMBANGAN KOPERASI LEMBAGA KEUANGAN MIKRO AGRIBISNIS (LKM-A) GAPOKTAN SARI MAKMUR KECAMATAN METRO TIMUR KOTA METRO
}

\author{
(Development Strategies of LKM-A Gapoktan Sari Makmur Cooperative in East Metro of Metro City)
}

Aurora Afifah Yasmin, Dyah Aring Hepiana Lestari, Muhammad Irfan Affandi

Jurusan Agribisnis, Fakultas Pertanian, Universitas Lampung, Jl. Prof. Dr. Soemantri Brojonegoro No. 1

Bandar Lampung 35145, Telp. 082176707837, e-mail: aurorafifah@gmail.com

\begin{abstract}
This research aims to analyze the internal and external environment, arrange development strategies, and determine priority strategies of Microfinance Institutions Farmer Groups Sari Makmur Cooperative. This research isperforms a case study method. Respondents were 13 people consist of organizers and members of the cooperative, expert, and regulator. Data analysis method used in this research was qualitative analysis method. The results showed that the main internal strengths of the cooperative were its legal status and registered status at the financial services authority. The main weakness was the lack of awareness of members in the cooperative. Externally, cooperative faced major opportunity in the form of the need for easy and fast loan services and the main threat of increasing community living costs. The priority strategies that could be used in the development and sustainability of the cooperative microfinance were using accounting software for financial data processing to improve cooperative's financial management, improving the quality of cooperative's organizer and managers by providing internal training and engaging in external training conducted by the government or other institutions, and improving the excellent service to meet the needs of cooperative's members.
\end{abstract}

Key words: cooperative, microfinance, strategies

\section{PENDAHULUAN}

Perkembangan ekonomi merupakan hal penting dan menjadi salah satu fokus pemerintah dalam membuat berbagai kebijakan untuk mencapai kesejahteraan. Pembangunan perekonomian di suatu negara memerlukan modal atau dana yang cukup besar dan program pembangunan disusun oleh lembaga-lembaga perekonomian yang telah ditentukan. Lembaga-lembaga perekonomian ini saling bekerja sama mengelola dan menggerakkan semua potensi ekonomi agar berdaya dan berhasil guna secara optimal (Felna 2012).

Pengembangan aktivitas ekonomi dapat dilakukan dengan berbagai alternatif kelembagaan. Namun, pengembangan aktivitas ekonomi yang berbasis kerakyatan memerlukan pendekatan yng memungkinkan partisipasi masyarakat secara luas dalam menjamin terjadinya pemerataan. Dalam hal ini, salah satu alternatif yang dapat ditempuh adalah melalui wadah koperasi serta melibatkannya dalam sistem kerja sama dengan berbagai pelaku dalam dunia usaha nasional.
Menurut UU No. 25 Tahun 1992, koperasi merupakan suatu badan usaha, sehingga koperasi tetap tunduk terhadap kaidah-kaidah perusahaan dan prinsip-prinsip ekonomi yang berlaku. Kebutuhan modal bagi sektor usaha kecil dan perkembangan koperasi yang meningkat setiap tahunnya membuat koperasi dituntut dapat menghasilkan keuntungan dalam mengembangkan organisasi dan usahanya. Oleh karena itu, koperasi diharapkan dapat berperan penting dalam perekonomian Indonesia sehingga koperasi dapat menjadi soko guru perekonomian.

Menurut Dinas Koperasi, UMKM, dan Perindustrian Kota Metro (2015), salah satu konsep perencanaan pengembangan usaha pembangunan di Kota Metro yang mengupayakan pembangunan pada sektor ekonomi sangat membutuhkan adanya perencanaan dan strategi yang matang. Kegiatan ekonomi yang berkembang di masyarakat akan sangat menunjang bagi terbukanya lapangan kerja, tingkat investasi yang tinggi, peluang akses permodalan, tingkat persaingan usaha baik industri, perdagangan dan jasa yang sehat. 
Koperasi yang berstatus aktif dan berperan dalam menumbuhkembangkan sektor pertanian di Kecamatan Metro Timur adalah Koperasi Lembaga Keuangan Mikro Agribisnis (LKM-A) Gapoktan Sari Makmur. Koperasi ini terdaftar dan mendapatkan izin usaha pada Otoritas Jasa Keuangan (OJK) per 30 April 2017 dengan nomor izin usaha KEP-74/NB.123/2016 pada tanggal 26 Oktober 2016. Tujuan koperasi ini sesuai dengan tujuan koperasi berdasarkan undang-undang, yaitu menyejahterakan anggotanya.

Koperasi LKM-A Gapoktan Sari Makmur memiliki unit usaha simpan pinjam. Latar belakang berdirinya koperasi ini adalah terbentuknya Gabungan Kelompok Tani (Gapoktan) Sari Makmur di Kecamatan Metro Timur pada tahun 2009. Pada tahun 2011 Gapoktan Sari Makmur menerima dana Pengembangan Usaha Agribisnis Pedesaan (PUAP).

Untuk meningkatkan kemampuan dan potensi koperasi dalam menjalankan usahanya, khususnya koperasi yang sedang mengalami proses pertumbuhan, dibutuhkan strategi yang tepat dan sesuai. Strategi yang tepat dan sesuai dengan kondisi lingkungan koperasi akan mampu meningkatkan kemampuan dan potensi yang dimiliki oleh koperasi. Lingkungan merupakan salah satu faktor terpenting untuk menunjang keberhasilan. Selain itu, untuk meningkatkan kemampuan dan potensi koperasi aktif, maka perlu dilakukan penelitian strategi pengembangan koperasi dengan cara menganalisis faktor eksternal dan internal koperasi.

Berdasarkan latar belakang tersebut, maka penelitian ini bertujuan untuk menganalisis lingkungan internal dan eksternal, menyusun strategi pengembangan, dan menentukan strategi prioritas Koperasi LKM-A Gapoktan Sari Makmur.

\section{METODE PENELITIAN}

Metode yang digunakan dalam penelitian ini adalah studi kasus. Penelitian dilakukan di Koperasi LKM-A Gapoktan Sari Makmur. Pemilihan lokasi dilakukan secara sengaja (purposive) dengan pertimbangan bahwa Koperasi LKM-A Gapoktan Sari Makmur merupakan satusatunya koperasi simpan pinjam di Kota Metro yang terdaftar pada OJK.
Responden dalam penelitian ini dipilih menggunakan metode non probability sampling. Responden yang digunakan untuk menjawab tujuan penelitian pertama dan ke dua sebanyak 13 orang yang terdiri dari 3 orang pengurus koperasi, 5 orang anggota koperasi, 1 orang pengawas, 1 orang manajer, 1 orang dosen Fakultas Pertanian Universitas Lampung, 1 orang perwakilan Dinas Koperasi, UMKM, dan Perindustrian Kota Metro, serta 1 orang perwakilan Dinas Pertanian Kota Metro.

Responden yang digunakan untuk menjawab tujuan penelitian ke tiga sebanyak 6 orang yang terdiri dari 3 orang pengurus koperasi, 1 orang dosen Fakultas Pertanian Universitas Lampung, 1 orang perwakilan Dinas Koperasi, UMKM, dan Perindustrian Kota Metro, serta 1 orang perwakilan Dinas Pertanian Kota Metro.

Data yang digunakan dalam penelitian ini terdiri dari data primer dan data sekunder. Data primer diperoleh dari wawancara pengurus koperasi, anggota koperasi, pakar, dan pengambil kebijakan di Kota Metro dengan menggunakan kuesioner dan pengamatan serta pencatatan langsung tentang keadaan koperasi. Data sekunder diperoleh dari instansi terkait dan studi literatur.

Faktor internal dan eksternal diperoleh dari analisis lingkungan internal dan eksternal Koperasi LKMA Gapoktan Sari Makmur. Faktor internal yang diidentifikasi meliputi komponen sumber daya manusia, manajemen, keuangan dan permodalan, unit usaha, dan administrasi. Selanjutnya faktor eksternal yang diidentifikasi meliputi ekonomi, teknologi, kebijakan pemerintah, dan pesaing.

Analisis SWOT digunakan untuk mengetahui aspek lingkungan internal dan eksternal koperasi serta strategi pengembangan Koperasi LKM-A Gapoktan Sari Makmur. Analisis SWOT membandingkan antara faktor eksternal peluang dan ancaman dengan faktor internal kekuatan dan kelemahan. Penyusunan strategi pengembangan pada penelitian melalui beberapa tahap.

Tahap pertama, menentukan faktor-faktor lingkungan internal dan lingkungan eksternal. Tahap ke dua, pemberian bobot dengan skala 1,0 (paling penting) sampai 0,0 (tidak penting) berdasarkan pengaruh faktor-faktor tersebut terhadap posisi strategis koperasi. Tahap ke tiga, menghitung rating dengan memberikan skala mulai dari 4 sampai dengan 1 dan tahap terakhir adalah mengalikan bobot dengan rating untuk 
menghasilkan skor pembobotan masing-masing faktor pada matriks IFE dan EFA. Matriks SWOT dapat dilihat pada Gambar 1.

\begin{tabular}{|c|c|c|}
\hline SWOT & $\begin{array}{l}\text { Strengths }(\mathrm{S}) \\
\text { Tentukan 5-10 } \\
\text { faktor yang } \\
\text { menjadi kekuatan }\end{array}$ & $\begin{array}{l}\text { Weakness (W) } \\
\text { Tentukan 5-10 } \\
\text { faktor yang } \\
\text { menjadi } \\
\text { kelemahan }\end{array}$ \\
\hline $\begin{array}{l}\text { Opportunities }(\mathrm{O}) \\
\text { Tentukan 5-10 } \\
\text { faktor yang } \\
\text { menjadi peluang }\end{array}$ & $\begin{array}{l}\text { Strategi (SO) } \\
\text { Ciptakan strategi } \\
\text { yang } \\
\text { menggunakan } \\
\text { kekuatan untuk } \\
\text { memanfaatkan } \\
\text { peluang }\end{array}$ & $\begin{array}{l}\text { Strategi (WO) } \\
\text { Ciptakan strategi } \\
\text { yang } \\
\text { meminimalkan } \\
\text { kelemahan untuk } \\
\text { memanfaatkan } \\
\text { peluang }\end{array}$ \\
\hline $\begin{array}{l}\text { Threats }(\mathrm{T}) \\
\text { Tentukan 5-10 } \\
\text { faktor yang } \\
\text { menjadi } \\
\text { ancaman }\end{array}$ & $\begin{array}{l}\text { Strategi (ST) } \\
\text { Ciptakan strategi } \\
\text { yang } \\
\text { menggunakan } \\
\text { kekuatan untuk } \\
\text { mengatasi } \\
\text { ancaman }\end{array}$ & $\begin{array}{l}\text { Strategi (WT) } \\
\text { Ciptakan strategi } \\
\text { yang } \\
\text { meminimalkan } \\
\text { kelemahan untuk } \\
\text { menghindari } \\
\text { ancaman }\end{array}$ \\
\hline
\end{tabular}

Sumber: Kuncoro 2005

\section{Gambar 1. Bentuk matriks SWOT}

Strategi yang sudah terbentuk dari matriks SWOT disusun berdasarkan prioritas yang diimplementasikan dengan menggunakan Quantitative Strategic Planning Matrix (QSPM). Matriks QSP digunakan untuk menentukan nilai daya tarik atau Attractiveness Score (AS) dan total nilai daya tarik atau Total Attractiveness Score (TAS) strategi yang disesuaikan dengan faktor internal dan eksternal. Matriks QSP dapat dilihat pada Tabel 1.

Tabel 1. Matriks quantitative strategi planning

\begin{tabular}{|c|c|c|c|c|c|}
\hline \multirow{3}{*}{$\begin{array}{c}\text { Faktor-faktor } \\
\text { kunci }\end{array}$} & \multirow{3}{*}{ Bobot } & \multicolumn{4}{|c|}{ Alternatif Strategi } \\
\hline & & \multicolumn{2}{|c|}{ Strategi 1} & \multicolumn{2}{|c|}{ Strategi 2} \\
\hline & & AS & TAS & AS & TAS \\
\hline \multicolumn{6}{|l|}{$\begin{array}{l}\text { Faktor } \\
\text { internal } \\
\text { Faktor } \\
\text { eksternal }\end{array}$} \\
\hline Jumlah & & & & & \\
\hline
\end{tabular}

Tabel 2. Skala penilaian perbandingan berpasangan

\begin{tabular}{cl}
\hline $\begin{array}{c}\text { Tingkat } \\
\text { Kepentingan }\end{array}$ & \multicolumn{1}{c}{ Definisi } \\
\hline 1 & $\begin{array}{l}\text { Kriteria/alternatif A sama penting dengan } \\
\text { kriteria/alternatif B }\end{array}$ \\
3 & A sedikit lebih penting dari B \\
5 & A jelas lebih penting dari B \\
7 & A sangat jelas lebih penting dari B \\
9 & Mutlak lebih penting dari B \\
$2,4,6,8$ & Apabila ragu-ragu antara dua nilai yang \\
& berdekatan \\
\hline
\end{tabular}

\section{Analytical Hierarchy Process (AHP)}

Metode AHP digunakan untuk menentukan strategi prioritas koperasi. Metode AHP adalah sebuah kerangka untuk mengambil keputusan dengan efektif atas persoalan yang kompleks dengan menyederhanakan dan mempercepat proses pengambilan keputusan dengan memecahkan persoalan tersebut ke dalam bagian-bagiannya. Selanjutnya menata bagian atau variabel ini dalam suatu susunan hirarki, memberi nilai numerik pada pertimbangan subjektif tentang pentingnya tiap variabel, dan mensintesis berbagai pertimbangan untuk menetapkan variabel mana yang memiliki prioritas paling tinggi (Marimin 2004). Hasil penilaian akan tampak lebih jelas bila disajikan dalam bentuk matriks Pairwise Comparison dengan menggunakan skala kepentingan pada Tabel 2.

\section{HASIL DAN PEMBAHASAN}

\section{Karakteristik Responden}

Responden pengurus, pengawas, dan manajer Koperasi LKM-A Gapoktan Sari Makmur memiliki tingkat pendidikan yang tinggi dan termasuk dalam kelompok umur produktif. Kemampuan pengurus Koperasi LKM-A Gapoktan Sari Makmur dalam mengelola kegiatan koperasi didukung oleh tingkat pendidikan dan pelatihanpelatihan yang pernah diikuti. Responden anggota Koperasi LKM-A Gapoktan Sari Makmur memiliki tingkat pendidikan yang rendah dan termasuk dalam kelompok umur produktif.

Responden dari bidang akademik diwakili oleh dosen tetap di Jurusan Agribisnis Fakultas Pertanian Universitas Lampung. Beliau memiliki pengalaman dalam membina lembaga keuangan mikro Baitul Maal wat Tamwil (BMT) di Provinsi Lampung dan Pusat Inkubasi Bisnis Usaha Kecil (PINBUK) selama 25 tahun. Responden dari pihak pemerintah diwakili oleh staff bidang koperasi pada Dinas Koperasi, UMKM, dan Perindustrian Kota Metro dan kepala bidang penyuluhan pertanian pada Dinas Pertanian Kota Metro.

\section{Analisis Lingkungan Internal}

Hasil dari identifikasi lingkungan internal koperasi adalah 8 faktor internal yang terdiri dari 4 faktor kekuatan dan 4 faktor kelemahan. Koperasi LKMA Gapoktan Sari Makmur memiliki sumber daya manusia berupa pengurus koperasi yang berpengalaman dalam berkoperasi. Namun, 
anggota koperasi memiliki tingkat pendidikan yang rendah dan kurangnya partisipasi dalam berkoperasi. Rapat Anggota Tahunan (RAT) Koperasi LKM-A Gapoktan Sari Makmur belum sepenuhnya berjalan, tetapi manajemen keuangan koperasi sudah diawasi langsung oleh OJK.

Koperasi LKM-A Gapoktan Sari Makmur hanya memiliki satu unit usaha, yaitu simpan pinjam. Administrasi dan pembukuan koperasi terorganisir dengan baik oleh pengurus koperasi. Kegiatan pencatatan di dalam Koperasi LKM-A Gapoktan Sari Makmur meliputi keanggotaan, kepengurusan, rapat anggota, simpanan anggota, dan lain sebagainya. Selain itu, Koperasi LKM-A Gapoktan Sari Makmur telah mendapatkan status badan hukum dan izin usaha OJK pada tahun 2016. Matriks IFE Koperasi LKM-A Gapoktan Sari Makmur dapat dilihat pada Tabel 3.

Faktor kekuatan berupa koperasi yang berbadan hukum dan terdaftar OJK memiliki bobot sebesar 0,1358 dan rating 4 yang menunjukkan faktor tersebut sangat kuat dibandingkan dengan pesaing sehingga menghasilkan skor sebesar 0,5432. Skor tertinggi pada faktor ini menunjukkan bahwa koperasi yang telah berbadan hukum dan terdaftar OJK memiliki pengaruh yang sangat kuat dalam pengembangan usaha Koperasi LKM-A Gapoktan Sari Makmur.

Faktor kelemahan berupa kurangnya partisipasi anggota dalam berkoperasi memiliki bobot sebesar 0,1234 dan rating 4 yang menunjukkan faktor tersebut sangat lemah terhadap pesaing sehingga menghasilkan skor sebesar 0,4936. Skor tertinggi pada faktor ini menunjukkan bahwa partisipasi anggota dalam berkoperasi sangat diperlukan dalam pengembangan usaha Koperasi LKM-A Gapoktan Sari Makmur.

\section{Analisis Lingkungan Eksternal}

Hasil dari identifikasi lingkungan eksternal koperasi adalah 6 faktor eksternal yang terdiri dari 3 faktor peluang dan 3 faktor ancaman.

Usaha di bidang agribisnis sangat bergantung pada faktor alam. Oleh karena itu, anggota Koperasi LKM-A Gapoktan Sari Makmur yang merupakan petani membutuhkan sumber modal untuk usahanya pada waktu yang tepat. Kebutuhan akan pelayanan pinjaman yang mudah dan cepat ini dapat menjadi peluang bagi Koperasi LKM-A Gapoktan Sari Makmur dalam meningkatkan jumlah anggota koperasi. Selain itu, perkembangan teknologi informasi dan adanya penyaluran dana PUAP dari pemerintah sebesar 100 juta rupiah merupakan peluang yang dapat dimanfaatkan oleh Koperasi LKM-A Gapoktan Sari Makmur.

Tabel 3. Matriks Internal Factor Evaluation (IFE) Koperasi LKM-A Gapoktan Sari Makmur

\begin{tabular}{|c|c|c|c|c|}
\hline No & Faktor Internal & Bobot & Rating & Skor \\
\hline & Kekuatan & & & \\
\hline A & $\begin{array}{l}\text { Pengurus koperasi } \\
\text { berpengalaman }\end{array}$ & 0,1275 & 3 & 0,3825 \\
\hline B & Koperasi berbadan & & & \\
\hline & $\begin{array}{l}\text { hukum dan terdaftar } \\
\text { OJK }\end{array}$ & 0,1358 & 4 & 0,5432 \\
\hline $\mathrm{C}$ & $\begin{array}{l}\text { Administrasi dan } \\
\text { pembukuan koperasi } \\
\text { terorganisir dengan } \\
\text { baik }\end{array}$ & 0,1249 & 3 & 0,3747 \\
\hline D & $\begin{array}{l}\text { Manajemen keuangan } \\
\text { koperasi diawasi } \\
\text { langsung oleh OJK }\end{array}$ & 0,1207 & 3 & 0,3621 \\
\hline & Kelemahan & & & \\
\hline $\mathrm{E}$ & $\begin{array}{l}\text { Hanya memiliki satu } \\
\text { unit usaha }\end{array}$ & 0,1235 & 3 & 0,3705 \\
\hline $\mathrm{F}$ & $\begin{array}{l}\text { Tingkat pendidikan } \\
\text { anggota koperasi } \\
\text { rendah }\end{array}$ & 0,1015 & 3 & 0,3045 \\
\hline G & $\begin{array}{l}\text { RAT yang belum } \\
\text { sepenuhnya berjalan }\end{array}$ & 0,1427 & 3 & 0,4281 \\
\hline $\mathrm{H}$ & $\begin{array}{l}\text { Kurangnya partisipasi } \\
\text { anggota dalam } \\
\text { berkoperasi }\end{array}$ & 0,1234 & 4 & 0,4936 \\
\hline & Total & 1,0000 & & 3,2592 \\
\hline
\end{tabular}

Tabel 4. Matriks External Factor Evaluation (EFE) Koperasi LKM-A Gapoktan Sari Makmur

\begin{tabular}{clccc}
\hline No & \multicolumn{1}{c}{ Faktor Eksternal } & Bobot & Rating & Skor \\
\hline A & $\begin{array}{l}\text { Peluang } \\
\text { Realisasi bantuan } \\
\text { dana dari pemerintah }\end{array}$ & 0,1928 & 3 & 0,5784 \\
B & $\begin{array}{l}\text { Perkembangan } \\
\text { teknologi informasi }\end{array}$ & 0,1826 & 2 & 0,3652 \\
C & $\begin{array}{l}\text { Kebutuhan akan } \\
\text { pelayanan pinjaman } \\
\text { yang mudah dan cepat }\end{array}$ & 0,2236 & 3 & 0,6708 \\
\hline D & $\begin{array}{l}\text { Ancaman } \\
\text { Persaingan antar } \\
\text { koperasi } \\
\text { Biaya hidup } \\
\text { masyarakat semakin } \\
\text { tinggi } \\
\text { Pesatnya } \\
\text { perkembangan kredit } \\
\text { mikro dari } \\
\text { perbankan/lembaga } \\
\text { keuangan }\end{array}$ & 0,0644 & 3 & 0,1932 \\
\hline Total & 0,1310 & 3 & 0,3930 \\
\hline
\end{tabular}


Persaingan usaha merupakan salah satu hal yang dapat menjadi kendala bagi pertumbuhan koperasi. Kecamatan Metro Timur memiliki koperasi dengan berbagai jenis unit usaha, seperti simpan pinjam, produksi, konsumsi, dan jasa. Kemudian pesatnya lembaga keuangan yang memberikan layanan pembiayaan atau kredit mikro seperti koperasi, BMT, dan lembaga perbankan lainnya dapat menjadi pembanding bagi anggota dalam memperoleh layanan simpan pinjam.

Biaya hidup masyarakat yang semakin meningkat dapat membuat anggota koperasi membutuhkan dana pinjaman untuk memenuhi kebutuhannya. Hal ini merupakan faktor eksternal ancaman bagi Koperasi LKM-A Gapoktan Sari Makmur dalam menjalankan usahanya. Matriks EFE Koperasi LKM-A Gapoktan Sari Makmur dapat dilihat pada Tabel 4.

Faktor peluang berupa kebutuhan akan pelayanan pinjaman yang mudah dan cepat memiliki bobot sebesar 0,2236 dan rating 3 yang menunjukkan respon usaha dalam meraih peluang tersebut di atas rata-rata sehingga menghasilkan skor sebesar 0,6708. Skor tertinggi pada faktor ini menunjukkan bahwa kebutuhan akan pelayanan pinjaman yang mudah dan cepat berpengaruh besar pada Koperasi LKM-A Gapoktan Sari Makmur.

\begin{tabular}{|c|c|c|c|}
\hline & & & \\
\hline 3,0 & $\begin{array}{c}\text { (1) } \\
\text { Growth }\end{array}$ & $\begin{array}{l}\text { (2) } \\
\text { Growth }\end{array}$ & $\begin{array}{c}(3) \\
\text { Retrench } \\
\text { ment }\end{array}$ \\
\hline & $\begin{array}{l}--(4)--0 \\
\text { Stability }\end{array}$ & $\begin{array}{c}\text { (5) } \\
\text { Growth } \\
\text { Stability }\end{array}$ & $\begin{array}{c}6) \\
\text { Retrench } \\
\text { ment }\end{array}$ \\
\hline & $\begin{array}{l}\text { (7) } \\
\text { Growth }\end{array}$ & $\begin{array}{c}\text { (8) } \\
\text { Growth }\end{array}$ & $\begin{array}{c}9) \\
\text { Retrench } \\
\text { ment }\end{array}$ \\
\hline
\end{tabular}

\section{Gambar 2. Matriks IE Koperasi LKM-A Gapoktan Sari Makmur}

Faktor ancaman berupa biaya hidup masyarakat yang semakin tinggi memiliki bobot sebesar 0,2056 dan rating 2 yang menunjukkan respon usaha terhadap ancaman tersebut di atas rata-rata sehingga menghasilkan skor sebesar 0,4112. Skor tertinggi pada faktor ini menunjukkan bahwa biaya hidup masyarakat yang semakin tinggi menjadi suatu ancaman terbesar yang dihadapi oleh Koperasi LKM-A Gapoktan Sari Makmur.

\section{Matriks Internal Eksternal (IE)}

Matriks IE merupakan pemetaan skor total IFE dan EFE dan digunakan untuk mengetahui arahan strategi yang akan dilaksanakan pada suatu usaha. Matriks IE Koperasi LKM-A Gapoktan Sari Makmur dapat dilihat pada Gambar 2.

Total skor IFE sebesar 3,2592 menunjukkan bahwa posisi internal koperasi kuat dan total skor EFE sebesar 2,6118 menunjukkan bahwa respon koperasi tergolong sedang terhadap lingkungan eksternalnya. Matriks IE pada Gambar 2 menunjukkan posisi usaha Koperasi LKM-A Gapoktan Sari Makmur berada pada sel IV yaitu stability strategy. Menurut Rangkuti (2006), stability strategy adalah strategi yang diterapkan tanpa mengubah arah strategi yang telah diterapkan.

Matriks tahap keputusan merupakan tahap yang terakhir untuk menentukan prioritas strategi terbaik yang akan dijalankan oleh suatu usaha melalui alternatif-alternatif strategi yang diperoleh dari hasil analisis SWOT. Dari 13 strategi yang dihasilkan oleh analisis SWOT, dilakukan pemberian skor alternatif yang disesuaikan dengan faktor internal dan eksternal yang ada. Skor alternatif tersebut dikalikan dengan bobot yang ada, sehingga dapat dihasilkan total skor alternatif. Delapan strategi prioritas utama menurut QSPM adalah sebagai berikut:

1. Koperasi menjalin hubungan kerjasama dengan lembaga keuangan lain (bank) untuk meningkatkan akses permodalan

2. Pemanfaatan modal sendiri koperasi dan bantuan dana pemerintah untuk mengoptimalkan unit usaha koperasi

3. Koperasi meningkatkan kualitas pengurus dan pengelola koperasi dengan cara pemberian pelatihan internal dan mengikutsertakan pelatihan eksternal yang diadakan pemerintah atau lembaga lain

4. Koperasi meningkatkan pelayanan yang prima dalam melakukan kegiatan simpan pinjam untuk memenuhi kebutuhan anggota

5. Penggunaan software akuntansi untuk pengolahan data keuangan koperasi sehingga dapat meningkatkan manajemen keuangan koperasi

6. Inovasi pendidikan/pelatihan bagi anggota koperasi

7. Koperasi mempertahankan pelaksanaan RAT rutin agar kegiatan koperasi dapat berjalan dengan baik

8. Sosialisasi untuk meningkatkan pemahaman tentang koperasi pada masyarakat Kelurahan Tejosari 
Delapan strategi prioritas utama di atas selanjutnya dianalisis dengan metode AHP menggunakan expert choice. Metode ini digunakan untuk menentukan prioritas strategi yang terdiri dari tiga tingkat, yaitu:

1. Tingkat pertama pada hirarki menyatakan tujuan, yaitu strategi pengembangan Koperasi Lembaga LKM-A Gapoktan Sari Makmur.

2. Tingkat ke dua pada hirarki menyatakan kriteria yang mempengaruhi strategi pengembangan koperasi, yaitu peningkatan kualitas SDM, manajemen koperasi, mengoptimalkan pelayanan dan pembinaan, serta penerapan teknologi.

3. Tingkat ke tiga merupakan delapan strategi menurut QSPM.

Menurut Saaty (1980), hasil pengolahan AHP dengan menggunakan expert choice dengan nilai konsistensi maksimal $10 \%$ menunjukkan bahwa nilai-nilai yang dihasilkan dari perhitungan dengan menggunakan program expert choice dapat dikatakan konsekuen dan dapat digunakan. Hasilnya adalah peningkatan kualitas SDM lebih penting dari manajemen koperasi, mengoptimalkan pelayanan dan pembinaan, serta penerapan teknologi dengan skor 5,288. Manajemen koperasi lebih penting dari mengoptimalkan pelayanan dan pembinaan dengan skor 2,080. Manajemen koperasi sedikit lebih penting dari penerapan teknologi dengan skor 1,732. Pengembangan Koperasi LKM-A Gapoktan Sari Makmur dapat dilakukan dengan kriteria utama yaitu peningkatan kualitas SDM.

Hasil penelitian ini sejalan dengan penelitian Sofwatama, Widjaya, dan Affandi (2017) yaitu strategi pengembangan BMT L-Risma yang memiliki skala prioritas tertinggi secara berturutturut adalah meningkatkan kualitas dan kuantitas SDM dengan cara pemberian pelatihan-pelatihan internal dan eksternal, mengoptimalkan pelayanan dan pembinaan usaha anggota untuk mendorong loyalitas dan minat anggota dalam memanfaatkan produk pembiayaan, meningkatkan efisiensi pelayanan dengan cara meningkatkan kompetensi pengelola divisi lending dalam memetakan (mapping) sasaran nasabah potensial.

Penelitian lain yang sejalan dengan penelitian ini adalah Rahmalia (2017) yang menganalisis tentang strategi pengembangan pembiayaan agribisnis pada koperasi simpan pinjam pola syariah dan pola konvensional di Kabupaten Lampung Tengah melalui pendekatan ANP (Analytic Network Process) didapatkan kesimpulan bahwa strategi prioritas dalam pengembangan pembiayaan agribisnis pada koperasi simpan pinjam pola syariah dan pola konvensional di Kabupaten Lampung Tengah adalah meningkatkan kualitas dan kuantitas SDM.

SDM dalam Koperasi LKM-A Gapoktan Sari Makmur merupakan hal yang penting karena dapat membantu dalam mencapai tujuan memajukan kesejahteraan anggota pada khususnya dan masyarakat pada umumnya serta ikut membangun tatanan perekonomian nasional dalam rangka mewujudkan masyarakat yang maju, adil, dan makmur.

Untuk mencapai tujuan strategi pengembangan Koperasi LKM-A Gapoktan Sari Makmur dapat dipilih tiga strategi prioritas, yaitu:

1. Penggunaan software akuntansi untuk pengolahan data keuangan koperasi sehingga dapat meningkatkan manajemen keuangan koperasi. Koperasi LKM-A Gapoktan Sari Makmur menggunakan Microsoft Excel dalam membuat laporan keuangan. Pembukuan menggunakan Microsoft Excel bersifat semi manual karena rumus-rumus perlu didefinisikan sendiri dan banyak hal lain yang harus dirancang sendiri oleh penggunanya.

Penelitian Dewi, Lestari, dan Adawiyah (2016) tentang kinerja, kesejahteraan anggota, dan strategi pengembangan koperasi (studi kasus pada koperasi "aktif" dan "tidak aktif" di Kabupaten Lampung Tengah) menyimpulkan bahwa strategi prioritas yang dapat digunakan dalam pengembangan KUD Tri Tunggal Sido Waras adalah menerapkan teknologi moderen guna meningkatkan penghasilan unit usaha koperasi. Prioritas strategi pada penelitian Dewi memiliki persamaan dengan penelitian ini, yaitu penggunaan software akuntansi untuk pengolahan data keuangan koperasi yang merupakan bentuk penerapan teknologi moderen untuk meningkatkan manajemen keuangan unit usaha koperasi.

2. Meningkatkan kualitas pengurus dan pengelola koperasi dengan cara pemberian pelatihan internal dan mengikutsertakan pelatihan eksternal yang diadakan pemerintah atau lembaga lain. Dengan mengikuti pelatihan, pengurus Koperasi LKM-A Gapoktan Sari Makmur akan memiliki kemampuan manajemen yang baik. Pengurus pun dapat menguasai teknologi berupa 
komputer yang mendukung kegiatan koperasi sehingga kebutuhan anggota dalam pelayanan pinjaman yang mudah dan cepat dapat terpenuhi.

Penelitian Sofwatama dkk (2017) menyimpulkan bahwa strategi prioritas yang dapat digunakan dalam pengembangan Lembaga Keuangan Mikro Syariah Baitul Maal Wat Tamwil L-Risma (LKMS BMT LRisma) di Provinsi Lampung adalah meningkatkan kualitas dan kuantitas SDM dengan cara pemberian pelatihan-pelatihan internal dan eksternal. Prioritas strategi pada penelitian Sofwatama memiliki persamaan dengan penelitian ini, yaitu meningkatkan kualitas pengurus dan pengelola koperasi dengan cara pemberian pelatihan internal dan eksternal sebagai bentuk peningkatan kualitas SDM koperasi.

3. Koperasi meningkatkan pelayanan yang prima dalam melakukan kegiatan simpan pinjam untuk memenuhi kebutuhan anggota. Pelayanan prima merupakan salah satu usaha yang dilakukan perusahaan untuk melayani pelanggan dengan sebaik-baiknya sehingga dapat memberikan kepuasan kepada pelanggan dan memenuhi kebutuhan serta keinginan pelanggan, baik berupa produk barang atau jasa. Dalam pelayanan prima terdapat dua elemen yang saling berkaitan, yaitu pelayanan dan kualitas.

Penelitian Irawan, Affandi, dan Kalsum (2013) menyimpulkan bahwa strategi prioritas yang dapat digunakan dalam pengembangan LKMS BMT Al Hasanah Sekampung adalah meningkatkan kualitas pelayanan. Hal ini sesuai dengan prioritas strategi yang perlu dilakukan oleh Koperasi LKM-A Gapoktan Sari Makmur, yaitu meningkatkan pelayanan yang prima dalam melakukan kegiatan simpan pinjam untuk memenuhi kebutuhan anggota.

\section{KESIMPULAN}

Secara internal, Koperasi LKM-A Gapoktan Sari Makmur memiliki kekuatan utama berupa koperasi yang berbadan hukum dan terdaftar pada Otoritas Jasa Keuangan (OJK) dan kelemahan utama berupa kurangnya partisipasi anggota dalam berkoperasi. Secara eksternal, Koperasi LKM-A Gapoktan Sari Makmur memiliki peluang utama berupa kebutuhan akan pelayanan pinjaman yang mudah dan cepat serta menghadapi ancaman utama berupa biaya hidup masyarakat yang semakin tinggi. Strategi prioritas yang dapat digunakan dalam pengembangan Koperasi LKM-A Gapoktan Sari Makmur adalah penggunaan software akuntansi untuk pengolahan data keuangan koperasi sehingga dapat meningkatkan manajemen keuangan koperasi, meningkatkan kualitas pengurus dan pengelola koperasi dengan cara pemberian pelatihan internal dan mengikutsertakan pelatihan eksternal yang diadakan pemerintah atau lembaga lain, dan koperasi meningkatkan pelayanan yang prima dalam melakukan kegiatan simpan pinjam untuk memenuhi kebutuhan anggota.

\section{DAFTAR PUSTAKA}

David F. 2002. Manajemen Strategi : KonsepKonsep. Edisi Ketujuh. PT.Prehellindo. Jakarta.

Dewi VS, Lestari DAH, dan Adawiyah R. 2016. Kinerja, kesejahteraan anggota, dan strategi pengembangan koperasi (studi kasus pada koperasi "aktif" dan "tidak aktif" di Kabupaten Lampung Tengah). JIIA. 5 (1): 7683. http://jurnal.fp.unila.ac.id/index.php/JIA/ article/view/1677/1503. [17 Oktober 2017].

Dinas Koperasi, UMKM, dan Perindustrian Kota Metro. 2015. Penyusunan Buku Koperasi dan UMKM. Dinas Koperasi, UMKM, dan Perindustrian Kota Metro. Metro.

Felna TA. 2012. Analisis permintaan kredit pada usaha mikro dan kecil di Kecamatan Medan Johor. Jurnal Ekonomi dan Keuangan. 1 (2): 30-40. http://download.portalgaruda.org/artic le.php?article $=58578 \&$ val $=4119$. $[17$ Oktober 2017].

Irawan D, Affandi MI, dan Kalsum U. 2013. Analisis strategi pengembangan Lembaga Keuangan Mikro Syariah (LKMS) Pedesaan (Studi Kasus BMT Al Hasanah Sekampung). JIIA. 1 (1): 1-9. http://jurnal.fp.unila.ac.id/ index.php/JIA/article/view/125/129. Oktober 2017].

Kuncoro. 2005. Otonomi dan Pembangunan Daerah: Reformasi, Perencanaan, Strategi, dan Peluang. Penerbit Erlangga. Jakarta.

Marimin. 2004. Teknik dan Aplikasi Pengambilan Keputusan Kriteria Majemuk. Grasindo. Jakarta.

Rahmalia D. 2017. Strategi Pengembangan Pembiayaan Agribisnis pada Koperasi Simpan Pinjam Pola Syariah dan Pola Konvensional di Kabupaten Lampung Tengah Melalui Pendekatan ANP (Analytic Network Process). 
Tesis. Fakultas Pertanian Universitas Lampung. Bandar Lampung.

Saaty TL. 1980. The Analytic Hierarchy Process. McGraw-Hill. New York.

Sofwatama H, Widjaya S, dan Affandi MI. 2017. Keberhasilan kinerja usaha Lembaga Keuangan Mikro Syariah Baitul Maal Wat
Tamwil L-Risma (LKMS BMT L-Risma) di Provinsi Lampung. JIIA. 5 (1): 57-66. http://jurnal.fp.unila.ac.id/index.php/JIA/articl e/view/1675/1501. [17 Oktober 2017].

Undang-Undang Perkoperasian Nomor 25 Tahun 1992 tentang Perkoperasian. Arsip DPR RI. Jakarta. 